UCRL-ID-142789

\title{
A Superconducting Detector System for High-Resolution Energy-Dispersive Soft X-Ray Spectroscopy
}

S. Friedrich ${ }^{1,2}$, T. Niedermayr ${ }^{2}$, O. Drury ${ }^{2}$, T. Funk ${ }^{1}$, M. Frank ${ }^{2}$ S. E. Labov ${ }^{2}$, S. P. Cramer ${ }^{1}$

${ }^{1}$ Lawrence Berkeley National Laboratory, Physical Biosciences Division University of California, Berkeley, California 94720, USA

${ }^{2}$ Lawrence Livermore National Laboratory, Advanced Detector Group Livermore, California 94551, USA

\section{February 21, 2001}




\section{DISCLAIMER}

This document was prepared as an account of work sponsored by an agency of the United States Government. Neither the United States Government nor the University of California nor any of their employees, makes any warranty, express or implied, or assumes any legal liability or responsibility for the accuracy, completeness, or usefulness of any information, apparatus, product, or process disclosed, or represents that its use would not infringe privately owned rights. Reference herein to any specific commercial product, process, or service by trade name, trademark, manufacturer, or otherwise, does not necessarily constitute or imply its endorsement, recommendation, or favoring by the United States Government or the University of California. The views and opinions of authors expressed herein do not necessarily state or reflect those of the United States Government or the University of California, and shall not be used for advertising or product endorsement purposes.

This work was performed under the auspices of the U. S. Department of Energy by the University of California, Lawrence Livermore National Laboratory under Contract No. W-7405-Eng-48.

This report has been reproduced directly from the best available copy.

Available electronically at http://www.doc.gov/bridge

Available for a processing fee to U.S. Department of Energy

And its contractors in paper from

U.S. Department of Energy

Office of Scientific and Technical Information

P.O. Box 62

Oak Ridge, TN 37831-0062

Telephone: (865) 576-8401

Facsimile: (865) 576-5728

E-mail: reports@adonis.osti.gov

Available for the sale to the public from

U.S. Department of Commerce

National Technical Information Service

5285 Port Royal Road

Springfield, VA 22161

Telephone: (800) 553-6847

Facsimile: (703) 605-6900

E-mail: orders@ntis.fedworld.gov

Online ordering: http://www.ntis.gov/ordering.htm

OR

Lawrence Livermore National Laboratory

Technical Information Department's Digital Library

http:/ / www.llnl.gov/tid/Library.html 


\title{
A Superconducting Detector System for High-Resolution Energy-Dispersive Soft X-Ray Spectroscopy
}

\author{
S. Friedrich ${ }^{1,2}$, T. Niedermayr ${ }^{2}$, O. Drury ${ }^{2}$, T. Funk ${ }^{1}$, M. Frank ${ }^{2}$ \\ S. E. Labov ${ }^{2}$, S. P. Cramer ${ }^{1}$ \\ ${ }^{1}$ Lawrence Berkeley National Laboratory, Physical Biosciences Division \\ University of California, Berkeley, California 94720, USA \\ ${ }^{2}$ Lawrence Livermore National Laboratory, Advanced Detector Group \\ Livermore, California 94551, USA
}

\section{INTRODUCTION}

Synchrotron-based soft x-ray spectroscopy is often limited by detector performance. Grating spectrometers have the resolution, but lack the efficiency for the analysis of dilute samples. Semiconducting $\mathrm{Si}(\mathrm{Li})$ or Ge detectors are efficient, but often lack the resolution to separate weak signals from strong nearby lines in multi-element samples. Superconducting tunnel junctions (STJs) operated at temperatures below $1 \mathrm{~K}$ can be used as high-resolution high-efficiency x-ray detectors. They combine high energy resolution around $10 \mathrm{eV}$ FWHM with the broad band efficiency of energy-dispersive detectors. We have designed a two-stage adiabatic demagnetization refrigerator (ADR) to operate STJ detectors in X-ray fluorescence measurements at beam line 4 of the ALS. We demonstrate the capabilities of such a detector system for fluorescence analysis of dilute metal sites in proteins and inorganic model compounds.

\section{THE DETECTOR SYSTEM}

Superconducting tunnel junction (STJ) x-ray detectors consist of two superconducting electrodes separated by a thin insulating barrier. They are based on measuring the excess tunneling current after $\mathrm{x}$-ray absorption in one of the electrodes generates excess free charge carriers in proportion to the $\mathrm{x}$-ray energy. In typical Nb-based STJ detectors, statistical fluctuations in the charge generation and tunneling processes limit the energy resolution to $4.3 \mathrm{eV}$ FWHM for $1 \mathrm{keV}$ photons. Their maximum pile-up limited count rate is determined by the life time of the excess charges of several $\mu \mathrm{s}$. Over the last decade, the Advanced Detector Group at Lawrence Livermore National Laboratory (LLNL) has been developing Nb-Al-AlOx-Al-Nb STJ detectors for x-ray astrophysics and national security applications. They have achieved an energy resolution between $1.7 \mathrm{eV}$ and $8.9 \mathrm{eV}$ FWHM for photon energies between $50 \mathrm{eV}$ and $1 \mathrm{keV}$, and they can be operated at count rates in excess of 10,000 counts/s [1,2].

In collaboration with the Advanced Detector Group at LLNL, we have developed a two-stage adiabatic demagnetization refrigerator (ADR) to operate STJ detectors in synchrotron-based xray fluorescence measurements (figure 1) [3]. Adiabatic demagnetization is a process of magnetic cooling below the temperature of a liquid helium bath by isothermal magnetization and adiabatic demagnetization of a paramagnetic material. Our ADR uses two different paramagnets. The first stage is cooled by a gallium gadolinium garnet (GGG) to $1 \mathrm{~K}$ and supports a second stage cooled by a ferric ammonium alum (FAA) paramagnet. This two-stage design attains a $60 \mathrm{mK}$ base temperature with 16 hours hold time per demagnetization cycle. It is reliable, easy to operate and does not require pumping on the liquid helium bath. 

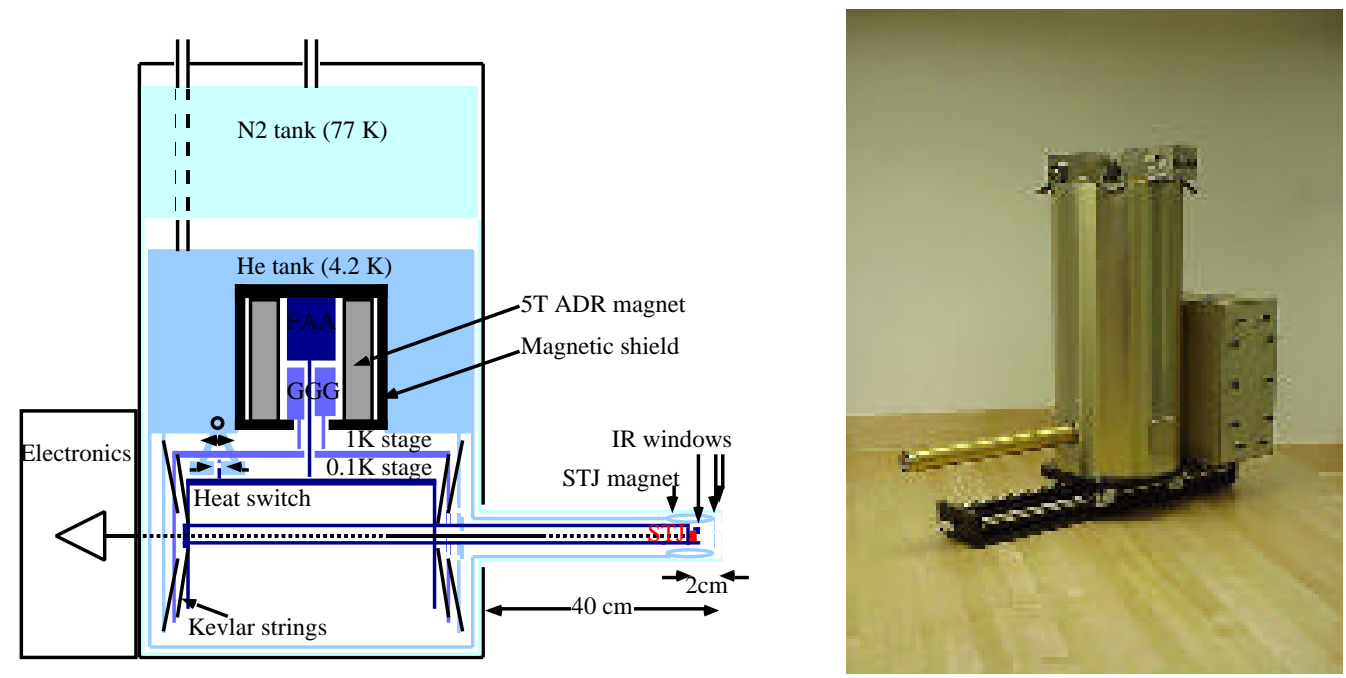

Figure 1. Schematic and photograph of the ADR cryostat. The STJ detector operates at a temperature of $0.1 \mathrm{~K}$ at the end of the detector snout that can be inserted into a UHV chamber.

To adapt this cryostat for x-ray fluorescence measurements, the STJ detector is held at the end of a $40 \mathrm{~cm}$ long cold finger that can be inserted into a sample chamber. A liquid $\mathrm{He}$ cooled and a liquid $\mathrm{N}_{2}$ cooled shield allow operation of the STJ detector behind three thin IR blocking windows within $2 \mathrm{~cm}$ of a room temperature sample in a UHV chamber at a pressure in the low $10^{-9}$ Torr range. The $\mathrm{x}$-ray induced signal is read out with a custom-designed FET preamplifier at room temperature followed by standard commercial pulse processing electronics.

\section{X-RAY FLUORESCENCE MEASUREMENTS}

We are interested in fluorescence detected absorption spectroscopy of transition metal L-edges in metalloenzymes and corresponding model compounds. Absorption spectra are taken by scanning the energy of the incident monochromatized synchrotron beam through an L-edge of interest to directly probe the empty states in the $3 \mathrm{~d}$ manifold. Since these $3 \mathrm{~d}$ levels are involved in chemical binding, absorption spectroscopy provides information about the metal oxidation state and the ligands, which in turn can be related to the catalytic mechanisms of the enzyme. For dilute metalloenzyme samples, the sensitivity of the absorption spectroscopy is enhanced by measuring the intensity of the corresponding L fluorescence line. STJ detectors are used to efficiently separate this fluorescence signal from nearby emission lines in cases where $\mathrm{Ge}$ detectors lack the energy resolution and grating spectrometers lack the detection efficiency.

Initial X-ray fluorescence tests of the STJ detector system were performed at beam line 4.0.2. at the ALS. Figure 2a shows a fluorescence spectrum of the metalloprotein hydrogenase of the bacterium D. Gigas containing $\approx 480 \mathrm{ppm}$ nickel and $\approx 5800 \mathrm{ppm}$ iron. The 2 -hour spectrum was acquired with a $100 \mu \mathrm{m} \times 100 \mu \mathrm{m}$ STJ with a detector-sample distance of $\approx 25 \mathrm{~mm}$. While the detector resolution between 11 and $25 \mathrm{eV}$ FWHM for the energy range between $277 \mathrm{eV}$ (C K) and $850 \mathrm{eV}(\mathrm{Ni} \mathrm{L})$ is still somewhat less than that of nominally identical detectors operated in an older cryostat without a snout [1], it is more than sufficient to separate the Fe $\mathrm{L}$ and the Ni L signal from the large $\mathrm{C} \mathrm{K}$ and $\mathrm{O} \mathrm{K}$ background. For comparison, we have included a fluorescence spectrum of the same protein taken with a commercial 30-element Ge detector. 

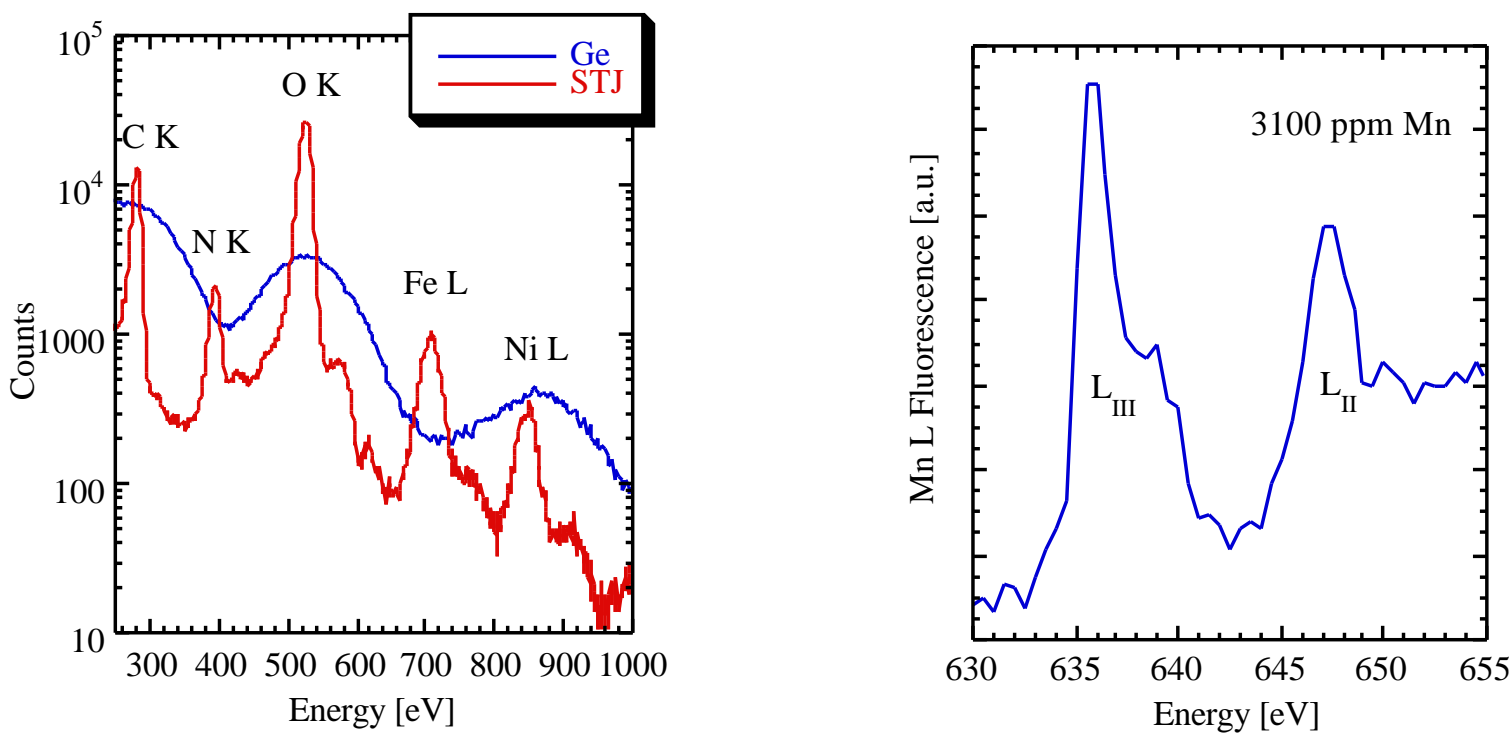

Figure 2a (left): Soft X-ray emission spectra of the metalloprotein hydrogenase containing about $480 \mathrm{ppm} \mathrm{Ni}$ and 5800 ppm Fe taken with the STJ detector system (red) and, for comparison, with a commercial 30-element Ge detector (blue). The Ni line is enhance in the Ge detector spectrum because of resonant excitation at the Ni L edge. Figure 2b (right): Fluorescence-detected L-edge absorption spectrum of 3100 ppm Mn in an MgO crystal.

The high energy resolution of STJ detectors allows fluorescence-detected absorption spectroscopy of dilute metals even in the presence of strong nearby emission lines. The fluorescence-detected absorption spectrum of $\mathrm{Mn}$ impurities in an $\mathrm{MgO}$ crystal in figure $2 \mathrm{~b}$ provides an illustrative example. It was taken with a single $200 \mu \mathrm{m} \times 200 \mu \mathrm{m}$ STJ in $\approx 1$ hour and is not affected by the $\mathrm{O} \mathrm{K}$ fluorescence at $525 \mathrm{eV}$. The spectra demonstrate how cryogenic STJ detectors can greatly enhance the sensitivity in soft X-ray spectroscopy of dilute samples.

\section{REFERENCES}

1. "Energy resolution and high count-rate performance of superconducting tunnel junction x-ray spectrometers", M. Frank, L. J. Hiller, J. B. LeGrand, C. A. Mears, S. E. Labov, M. A. Lindeman, H. Netel, D. Chow and A. T. Barfknecht, Rev. Sci. Inst. 69, 25 (1998)

2. "High-resolution tunnel Junction Extreme Ultraviolet Detectors Limited by Quasiparticle Counting statistics", S. Friedrich, J. B. LeGrand, L. J. Hiller, J. Kipp, M. Frank, S. E. Labov, S. P. Cramer, A. T. Barfknecht, IEEE Trans. Appl. Superconductivity 9, 3330 (1999)

3. "A superconducting detector endstation for high-resolution energy-dispersive SR-XFR", S. Friedrich, T. Niedermayr, O. Drury, M. F. Cunningham, M. L. van den Berg, J. N. Ullom, A. Loshak, T. Funk, S. P. Cramer, J. D. Batteux, E. See, M. Frank, S. E. Labov, accepted for publication in Nucl. Inst. Meth. (2001)

This work was performed under the auspices of the U.S. Department of Energy by University of California Lawrence Livermore National Laboratory under contract No. W-7405-Eng-48. Funding was provided by the NASA SADD grant NAG 5-4137, the NASA High Energy Astrophysics SR\&T agreement W19.121, the NIH grant GM 44380, the NASA Constellation X program under S-10256G and the DOE OBER.

Principal investigator: Stephen P. Cramer, Physical Biosciences Division, Ernest Orlando Lawrence Berkeley National Laboratory, 1 Cyclotron Road, MS 6-2100 Email: cramer@lbl.gov. Telephone: 510-486-4720. 